\title{
PROTECTIVE AND CURATIVE EFFECTS OF FRESH ORANGE JUICE (CITRUS SINENSIS L.) SUPPLEMENTATION AGAINST LIVER INJURIES, HEPATIC LIPID, PROTEIN, AND DNA- OXIDATIVE DAMAGE INDUCED CYCLOOXYGENASE-2/PROSTAGLANDIN E2 INFLAMMATORY PATHWAY IN FEMALE IRRADIATED RATS
}

\author{
GEHAN M MORSY, ALYAE MS GABAL* \\ Department of Biochemistry and Nutrition, Women's College, Ain Shams University, Cairo, Egypt. Email: alyeesalah@gmail.com \\ Received: 24 June 2020, Revised and Accepted: 28 July 2020
}

ABSTRACT

Objective: Our study aimed to examine the protective and curative ability of fresh orange juice (OJ) (Citrus sinensis L.) to counteract the adverse side effects of ionizing radiation (IR) on hepatic tissues of female irradiated rats and that has not been studied in advance.

Methods: Forty-nine adult female Sprague-Dawley albino rats $(170 \pm 5$ g) were divided into four sets of 12 animals, except the healthy control group contained 10 rats only and the irradiated control group contained 15 rats and was divided as follow Group I: Healthy control; Group II: Irradiated control, rats receiving a single dose (20 gray absorbed dose [Gy]) of whole-body $\gamma$-rays; Group III: Protective group, rats received (5 ml 0J/kg body weight) once daily for 14 days and after $24 \mathrm{~h}$ exposed to irradiation; and Group IV: Curative group, then rats were submitted to irradiation than after $24 \mathrm{~h}$, treated with ( $5 \mathrm{ml} \mathrm{OJ/kg} \mathrm{body} \mathrm{weight)} \mathrm{once} \mathrm{every} \mathrm{day} \mathrm{for} 14$ successive days.

Results: Our results explored that fresh OJ contains significant amounts of antioxidants as flavonoids and polyphenols and consequently pre- or post-fresh OJ supplementation to female irradiated rats attenuated significantly $(\mathrm{p} \leq 0.05)$ hepatic lipid, protein, and DNA-oxidative damage, hepatic inflammation, and activated inflammatory cyclooxygenase-2/prostaglandin E2 pathway, liver fibrosis, impaired liver functions, and hepatic lipid metabolism when compared with irradiated control rats. Furthermore, fresh OJ improved significantly ( $\mathrm{p} \leq 0.05)$ the hepatic antioxidant capacity in protective and curative groups in comparison with the irradiated control group.

Conclusion: The current research illustrated that fresh OJ may improve and normalize the various hepatic biochemical abnormalities resulted from irradiation due to its high content of active constituents of flavonoids and polyphenols. It is advised for people who exposed to IR, especially females, to consume about ( $5 \mathrm{ml} \mathrm{OJ/kg} \mathrm{body} \mathrm{weight)} \mathrm{before} \mathrm{exposure} \mathrm{as} \mathrm{the} \mathrm{most} \mathrm{significant} \mathrm{improvements} \mathrm{were} \mathrm{recorded} \mathrm{in} \mathrm{the} \mathrm{protective} \mathrm{group}$ that supplemented with $0 \mathrm{~J}$ before irradiation.

Keywords: Orange juice, Irradiation, Female, Oxidative DNA-damage, Hepatic tissues impairment and cyclooxygenase-2/prostaglandin E2 inflammatory pathway.

(C) 2020 The Authors. Published by Innovare Academic Sciences Pvt Ltd. This is an open access article under the CC BY license (http://creativecommons. org/licenses/by/4. 0/) DOI: http://dx.doi.org/10.22159/ajpcr.2020.v13i10.38855

\section{INTRODUCTION}

Citrus fruits and juices are considered as an essential source of active components as flavonoids, phenolic compounds, ascorbic acid, and pectins. Good human nutrition requires these active components regularly. Three types of flavonoids (flavones, flavanones, and flavonols) are found in citrus fruits. The main flavonoids found in citrus fruits are hesperidin, naringin, eriocitrin, and narirutin [1].

The use of natural products as medicines has been described throughout history as various plants show a significant role in protecting human beings from various simple to life-threatening diseases. Due to this reason, a large number of peoples of the developing countries still rely on herbal medicines [2].

Orange (C. sinensis $\mathrm{L}$.) juice (OJ) contains a variety of strong antioxidants such as flavonoids (hesperetin and naringenin predominantly as glycosides), carotenoids (xanthophylls, carotenes, and cryptoxanthin), and folic and ascorbic acids associated with other beneficial phytochemicals and minerals. All these compounds are found to have pharmacological activity as radical scavengers and to be significant contributors in the prevention of different human diseases [3].

Ionizing radiation (IR) became one of the most environmental toxicants used in modern medicine for diagnostic and therapeutic purposes. IR is used in cancer treatment and largely in industry and its applications such as improving new diversities of high-yield crops and increasing shelf life of food materials. Exposure to IR causes different changes in the function and structure of cellular components. IR exposure may lead to tissue damage, and in some cases, may cause death depending on different factors. These factors include absorbed dose, irradiation duration, interval after exposure, and its tendency to initiate a series of reactions that increase the levels of free radicals in cells and tissues [4].

The liver is a metabolically active organ that can be easily influenced by various environmental conditions as IR. Considerably, high-dose radiations (such as 2 gray, absorbed dose [Gy]/day in fractional irradiation as cancer radiotherapy) can have various effects depending on the area to be exposed and age at which exposure happen [5]

Radiation has different effects on the liver, such as fibrosis and liver cancer resulting from a high dosage of irradiation in cancer radiotherapies. This is because liver's active metabolism initiates reactions to radiation. The effects of liver radiation can be exacerbated by other environmental factors such as high-calorie foods or alcoholic drinks. Accommodation to other environmental conditions could also influence the radiation effects. Response to radiation cannot be easily controlled under conditions modulated by the environment, possibly progressing to dysregulation, illness, or cancer [6]. 
There are not any previous reports about the effect of $\mathrm{OJ}$ administration on the irradiated rats and hence we will explore the protective and curative effects of $\mathrm{OJ}$ supplementation against liver impairment, hepatic oxidative status, oxidative DNA-damage, and inflammationinduced cyclooxygenase-2/prostaglandin E2 (COX-2/PGE2) pathway in female irradiated rats for the $1^{\text {st }}$ time. We chose female rats due to the increased incidence of breast and uterine cancers among females and that is usually associated with radiotherapy.

\section{MATERIALS AND METHODS}

\section{Materials}

Plants

Organic orange (C. sinensis L.) was purchased from Ministry of Agriculture, Cairo, Egypt. (December 2020) and verified by a botanist (Department of Botany, Women's college, Ain shams University).

Diet

Standard commercial diet [7] obtained from Egyptian Organization for Biological Products and Vaccines (Helwan, Egypt).

\section{Animals}

Forty-nine adult female albino rats of Sprague-Dawley strains weighing (170 \pm 5 g) were supplied by Egyptian Organization for Biological Products and Vaccines (Helwan, Egypt). All animal experimentation were done in accordance with the Committee for the Purpose of Control and Supervision of Experiments on Animals guidelines and were authorized by the Institutional Animal Ethics Committee.

\section{Methods}

Preparation of fresh $0 \mathrm{~J}$

Fresh OJ was prepared just before administration using $C$. sinensis L., organic oranges (free of agrochemicals). After peeling the fruit, fresh juice was squeezed out of the fruit and was immediately used after filtration. C. sinensis juice was given orally in a moderate dose $(5 \mathrm{ml} / \mathrm{kg}$ body weight) to tested rats. Glass recipients containing the juice were coated to avoid light exposure [8].

Measurement of total polyphenols and flavonoids contents as well as total antioxidant activity of fresh $0 \mathrm{~J}$ samples

The amount of total polyphenols and total flavonoids content in fresh OJ were determined by Folin-Ciocalteu reagent $[9,10]$, respectively. Total antioxidant activity of juice was estimated by the 1,1-diphenyl-2 picrylhydrazyl method [11]. The experiments were repeated in triplicate.

\section{Irradiation}

Irradiation was performed to anesthetized rats with 137 Cesium, $\gamma$-radiation source $(\gamma$-Cell-40 manufactured by the Atomic Energy of Canada, Ltd.) at The National Center for Radiation Research and Technology. The dose rate was $(0.42 \mathrm{~Gy} / \mathrm{min})$.

\section{Experimental design}

All rats were housed individually with constant controlled environments in stainless steel cages and fed on the balanced commercial diet with drinking water ad libitum for 1 week (acclimatization period). Animals classified randomly into four sets of 12 animals, except healthy control group which contained 10 rats and irradiated control group which contained 15 rats. Rats were treated as follows: Group 1: Healthy controls, rats ingested (5 ml tap water/kg body weight) through an intra-gastric tube once daily for 14 days, Group 2: Irradiated controls, rats exposed to single dose (20 Gy) of whole-body $\gamma$-rays [12] and received (5 ml tap water $/ \mathrm{kg}$ body weight) through intra-gastric tube once daily for 14 days, Group 3: Protective group, rats received ( $5 \mathrm{ml} \mathrm{OJ} / \mathrm{kg}$ body weight) through an intra-gastric tube once daily for 14 days and after $24 \mathrm{~h}$ exposed to (20 Gy) of $\gamma$-rays, and Group 4: Curative group, rats were submitted to $(20 \mathrm{~Gy}) \gamma$-rays then after $24 \mathrm{~h}$, treated with ( $5 \mathrm{ml} 0 \mathrm{~J} / \mathrm{kg}$ body weight)via intra-gastric tube once every day for 14 consecutive days.

\section{Handling of blood and liver specimens}

By the end of the experiment, rats were allowed to fast all night and were sacrificed under sodium barbiturate anesthesia. Blood samples were obtained from the hepatic portal vein; serum was separated for doing the biochemical examinations. Liver samples were separated, rinsed, dried on filter paper, homogenized in Tris hydrochloride (Tris$\mathrm{HCl}$ ) buffer ( $\mathrm{pH}$ 7.4), and centrifuged. The supernatants which resulted were stored at $-80^{\circ} \mathrm{C}$ immediately until doing the biochemical analysis.

\section{Biochemical analysis}

Hepatic malondialdehyde (MDA), reduced glutathione (GSH) and protein carbonyl group (PCG) levels as well as glutathione peroxidase (GSH-PX), superoxide dismutase (SOD), and COX-2 activities were determined according to Draper and Hadley, Beutler et al., Reznick and Packer, Paglia and Valentine, Misra and Fridovich and Kulmacz and lands [13-18]. Hepatic DNA oxidative marker 8-hydroxydeoxyguanosine (8-OHdG), PGE2, and tumor necrosis factor-alpha (TNF- $\alpha$ ) levels were determined using Cell Biolabs and Koma Biotech Elisa kits.

Serum activities of alanine aminotransferase (ALT), aspartate aminotransferase (AST), $\gamma$-glutamyltransferase, and alkaline phosphatase (ALP) as well as serum total bilirubin level were evaluated using kits of biodiagnostic while liver collagen level was determined using Biovision kit. Furthermore, hepatic total lipids, total cholesterol, and triglyceride levels were estimated according to MacDonald, Richmond and Bucolo and David [19-21].

\section{Statistical analysis}

Results were expressed as mean \pm standard deviation of the mean. The SPSS package version 16 was used to review the differences between means for statistical significance by a one-way study of variance. Statistical significance was inspected when $p \leq 0.05$ [22].

\section{RESULTS}

OJ total flavonoids, total polyphenols content, and total antioxidant capacity

Table 1 illustrated that $0 \mathrm{~J}$ has a high content of active components such as flavonoids and polyphenols and consequently has a high antioxidant capacity that can decrease and ameliorate the side effects of irradiation.

Effect of protective and curative $0 \mathrm{~J}$ supplementation on hepatic lipid peroxidation, protein oxidation, and oxidative DNA damage parameters in irradiated female rats

The results illustrated in Fig. 1a-c showed that irradiation of female rats increased hepatic lipid peroxidation, protein oxidation, and induced oxidative DNA damage $(\mathrm{p} \leq 0.05)$ on comparison with healthy control rats. On the other hand, pre- and post-fresh OJ supplementation attenuated these deleterious effects. Pre- and post-OJ supplementation decreased elevated hepatic MDA, PCG, and 8-OHdG levels and the most improvements were found in the protective group $(\mathrm{p} \leq 0.05)$ compared to the irradiated control group.

Impact of protective and curative $0 \mathrm{~J}$ supplementation on hepatic antioxidant status in irradiated female rats

The results of the current study revealed that $\mathrm{OJ}$ contains significant amounts of active constituents that ameliorated decreased activity and level of hepatic antioxidants induced by irradiation, as shown in Fig. 2a-c. Results cleared that pre-treatment of irradiated rats with $0 \mathrm{~J}$

Table 1: Orange juice total flavonoids, total polyphenols, and total antioxidant capacity

\begin{tabular}{ll}
\hline Parameter & Orange juice content \\
\hline $\begin{array}{l}\text { Total flavonoids }(\mathrm{mg} / 1 \mathrm{ml} \text { fresh juice) } \\
\text { Total polyphenols }(\mathrm{mg} \text { gallic acid } \\
\text { equivalents } / 1 \mathrm{ml} \text { fresh juice) }\end{array}$ & 0.41 \\
Total antioxidant capacity (\%) & 6.8 \\
\hline
\end{tabular}




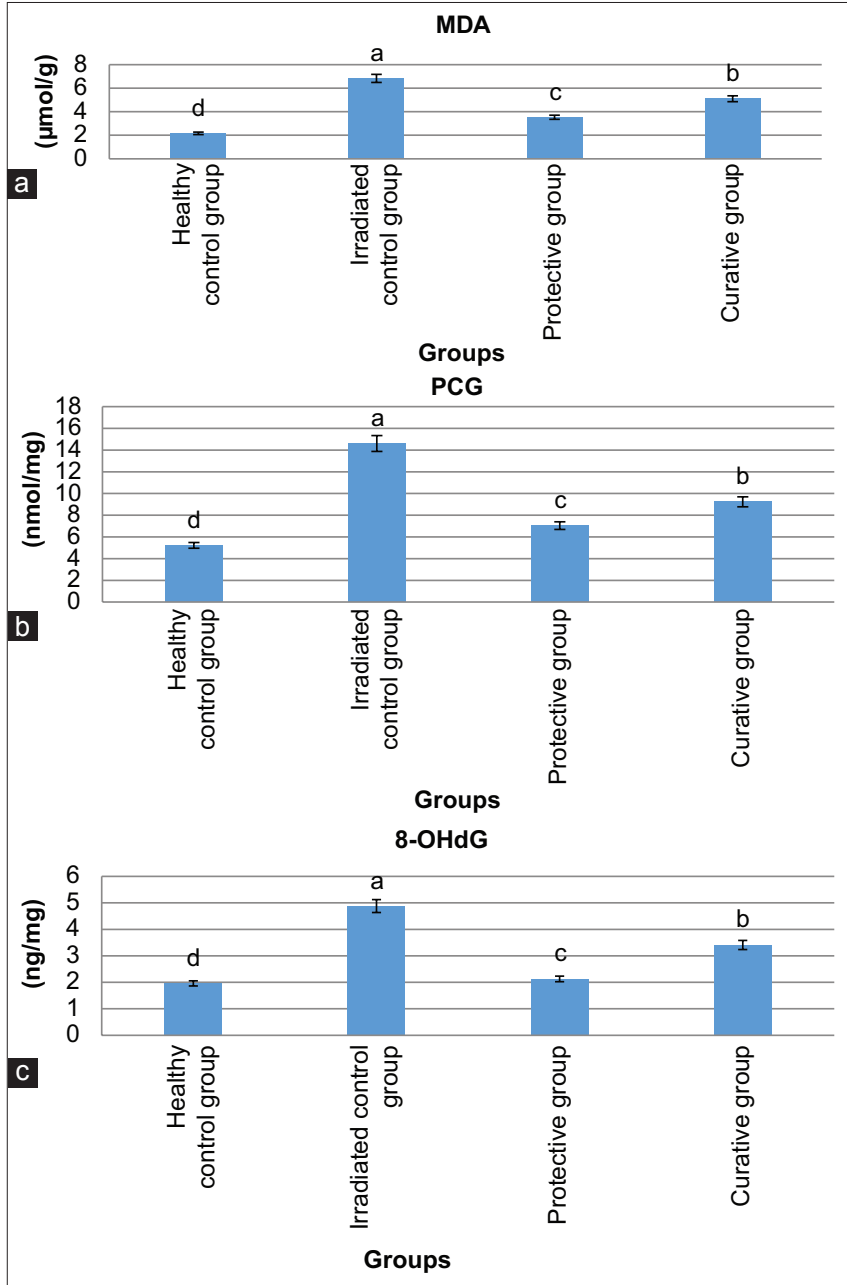

Fig. 1: Effect of protective and curative orange juice supplementation on hepatic lipid peroxidation malondialdehyde (a), protein oxidation (b), and oxidative DNA damage 8- hydroxydeoxyguanosine (c) levels in irradiated female rats. Values are expressed as means \pm standard deviation, $n=10$. Column of histogram with different letters is significantly different at $(p \leq 0.05)$

improved the hepatic antioxidant status $(\mathrm{p} \leq 0.05)$ more than the posttreated group when compared to the irradiated control group.

Effect of protective and curative $0 J$ supplementation on hepatic inflammatory and tissue damage markers in irradiated female rats Data for inflammatory and tissue damage parameters were illustrated in Fig. 3a-d. In regard to COX-2 activity, PGE2, TNF- $\alpha$, and collagen levels, the exposure of female rats to gamma radiation significantly increased $(p \leq 0.05)$ the activity of hepatic COX-2 and the concentrations of PGE2, TNF- $\alpha$, and collagen as compared to their equivalents in controls. The pre- and post-administration of $\mathrm{OJ}$ to irradiated female rats persuade significant amelioration $(\mathrm{p} \leq 0.05)$ in all parameters. The most significant ameliorations were found in the protective group.

Impact of protective and curative OJ supplementation on serum liver functioning enzymes, ALP activities, and total bilirubin level in irradiated female rats

Irradiation of experimental female rats in Fig. 4a-e caused a significant increment $(\mathrm{p} \leq 0.05)$ in serum liver functioning enzymes and ALP activities as well as bilirubin level on comparison with the healthy control group. On the contrary, supplementation with OJ caused significant improvements $(\mathrm{p} \leq 0.05)$ in all parameters and most improvements were found in the protective group.

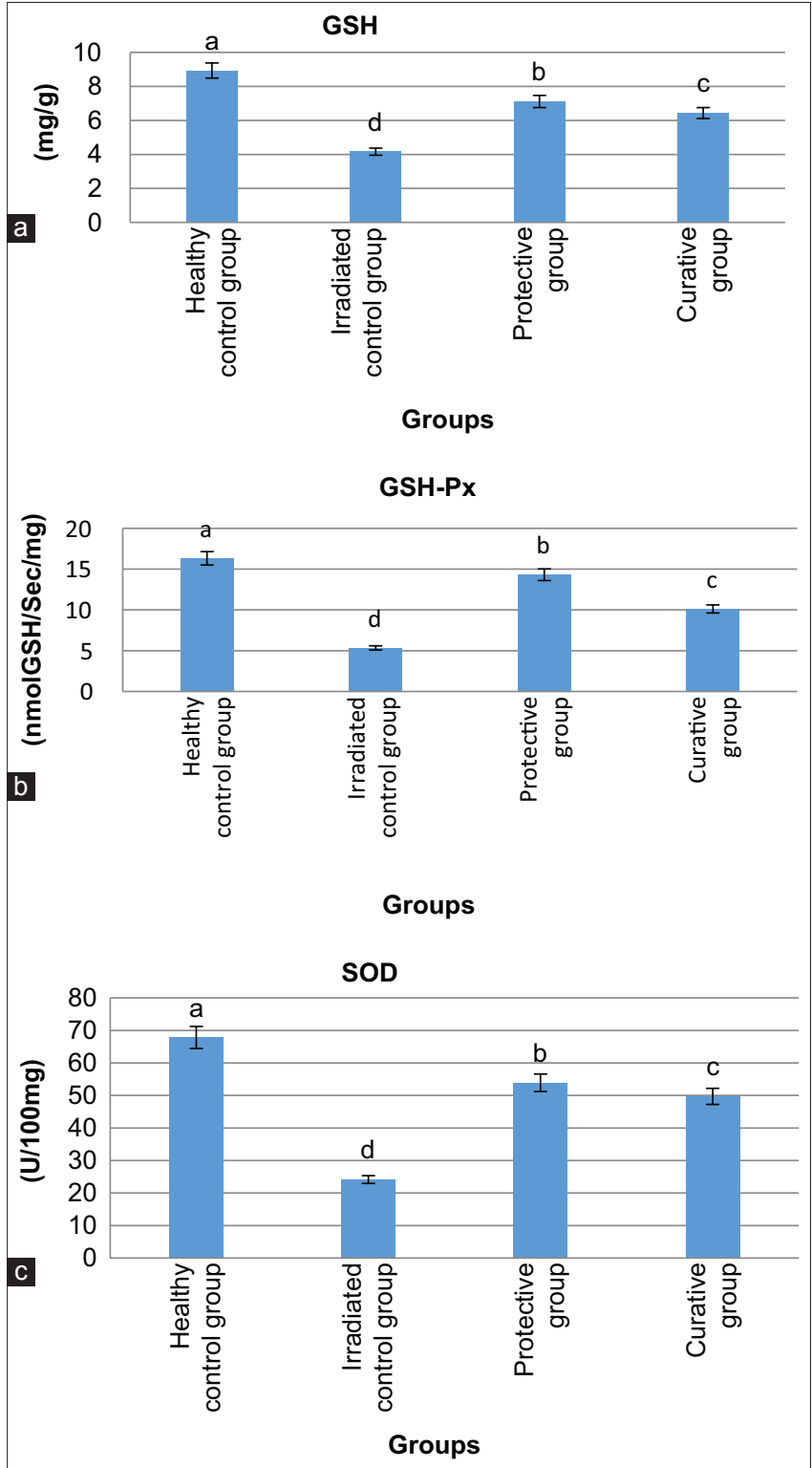

Fig. 2: Impact of protective and curative orange juice supplementation on hepatic antioxidant status glutathione (a) level, glutathione peroxidase (b), and superoxide dismutase (c) activities in irradiated female rats. Values are expressed as means \pm standard deviation, $n=10$. Column of histogram with different letters is significantly different at $(p \leq 0.05)$

Effect of protective and curative $0 \mathrm{~J}$ supplementation on hepatic lipid profile in irradiated female rats

In this figure, Fig. $5 a-c$, there was a significant increase $(p \leq 0.05)$ in lipid parameters in the liver of the irradiated control group as compared to the healthy control group. While pre- and post-OJ supplementation enhanced these results significantly $(p \leq 0.05)$, especially the protective group that pre-supplemented with fresh $0 \mathrm{~J}$.

\section{DISCUSSION}

OJ is the most popular of all the fruit juices. Our results declared that OJ contains a significant amount of active constituents such as flavonoids and polyphenols. Main antioxidant and active components found in OJ include flavonoid glycosides (hesperidin and naringenin), carotenoids (xanthophylls and cryptoxanthin), terpenoids ( $\alpha$-terpineol and limonene), ascorbic, and folic acids. Ingestion of $\mathrm{OJ}$ was found to improve the whole body antioxidant 


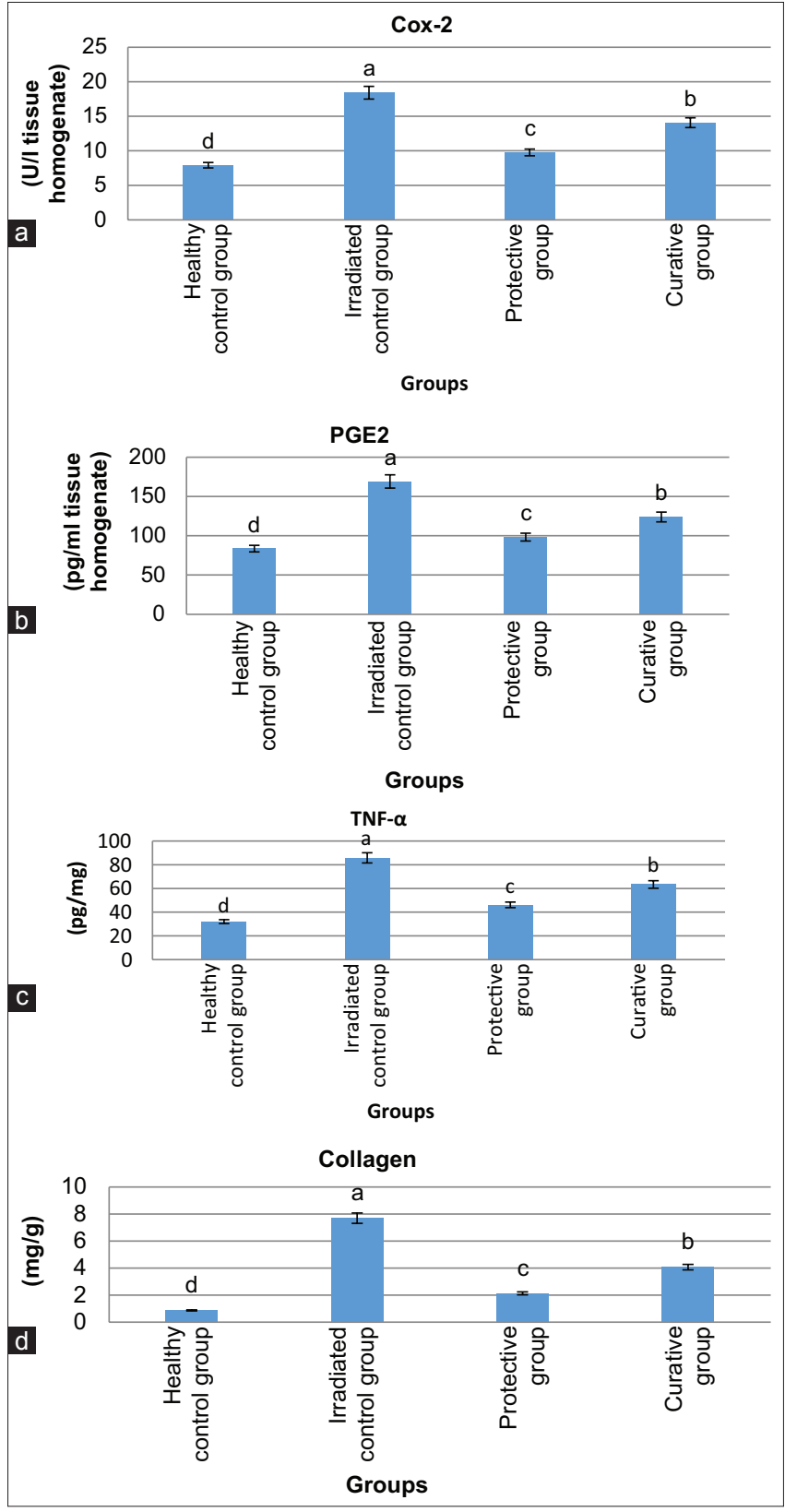

Fig. 3: Effect of protective and curative orange juice supplementation on hepatic inflammatory markers cyclooxygenase-2 (a) activity, prostaglandin E2 (b), tumor necrosis factor-alpha (c), and tissue damage indicator [Collagen

(d)] levels in irradiated female rats. Values are expressed as means \pm standard deviation, $\mathrm{n}=10$. Column of histogram with different letters is significantly different at $(p \leq 0.05)$

status, prevent, and cure different diseases. Our findings were approved by other studies $[8,23,24]$.

IR is usually used for curing cancer patients. Exposure to high doses of IR is associated with the utilization of oxygen by cells resulting in the production of highly reactive free radicals. IR generates reactive oxygen species (ROS). Imbalance between ROS and antioxidants level and activity leads to oxidative stress implicating tissue damage and appears in several forms of cellular injury. Liver is a very active metabolizing organ and when the body exposed to IR liver tissues respond by increasing production of ROS, resulting in increased hepatic lipid peroxidation indicator (MDA), protein oxidation (PCG) marker, and hepatic oxidative -DNA damage indicator $(8-\mathrm{OHdG})$ leading to a state of massive oxidation in irradiated liver tissues. On the other hand, antioxidant defense system capacity of the

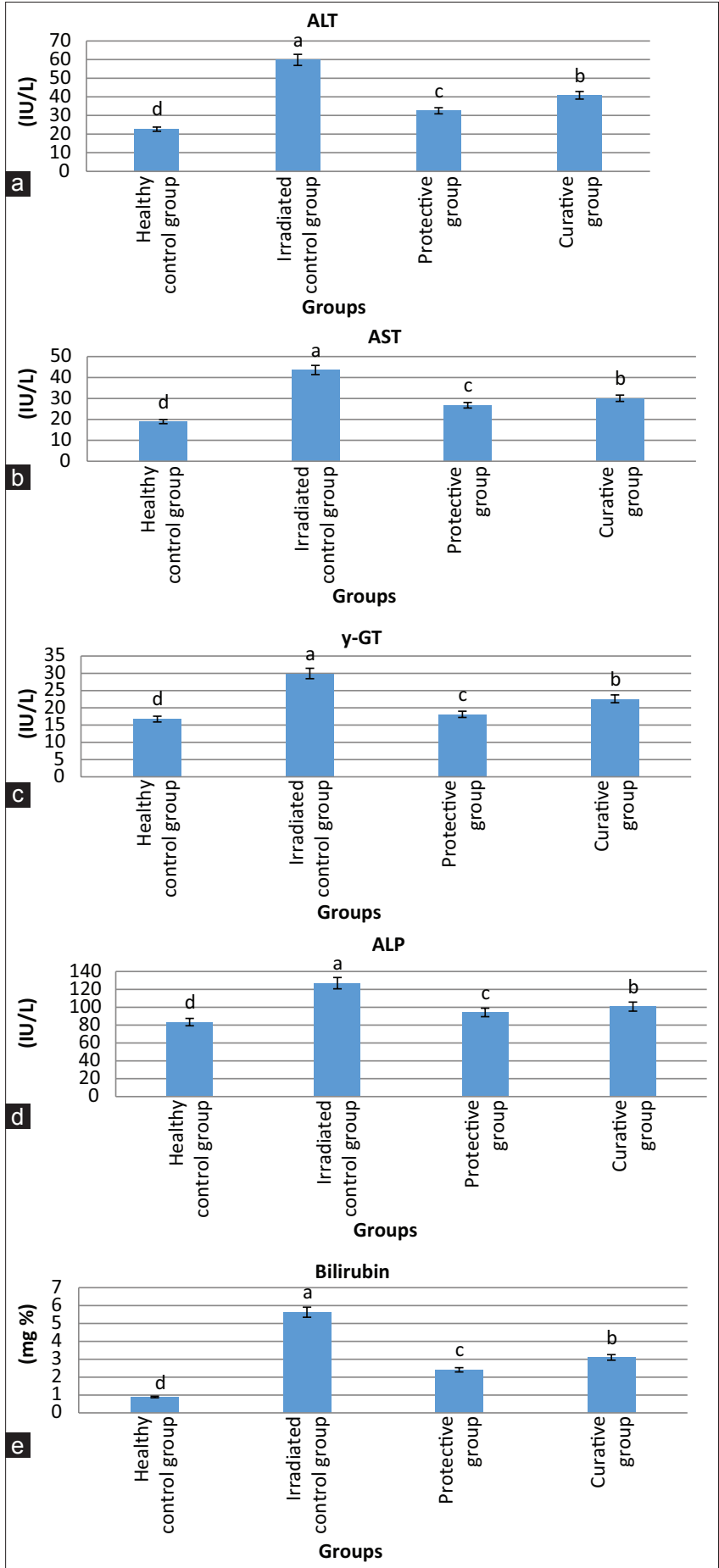

Fig. 4: Impact of protective and curative orange juice supplementation on serum liver functioning enzymes alanine aminotransferase, aspartate aminotransferase, $\gamma$-glutamyltransferase respectively, alanine aminotransferase (a), aspartate aminotransferase (b) and y-GT (c) and alkaline phosphatase (d) activities as well as [bilirubin (e)] level in irradiated female rats. Values are expressed as means \pm standard deviation, $n=10$. Column of histogram with different letters is significantly different at $(p \leq 0.05)$

irradiated liver has decreased as a result of decreased hepatic GSH level as well as hepatic GSH-PX and SOD activities which are considered as strong liver antioxidants. Our results go hand in hand with Cheng et al. [12,25-30].

OJ flavonoids and polyphenols attenuate the hepatic oxidative status induced by irradiation and that was clarified by decreased 


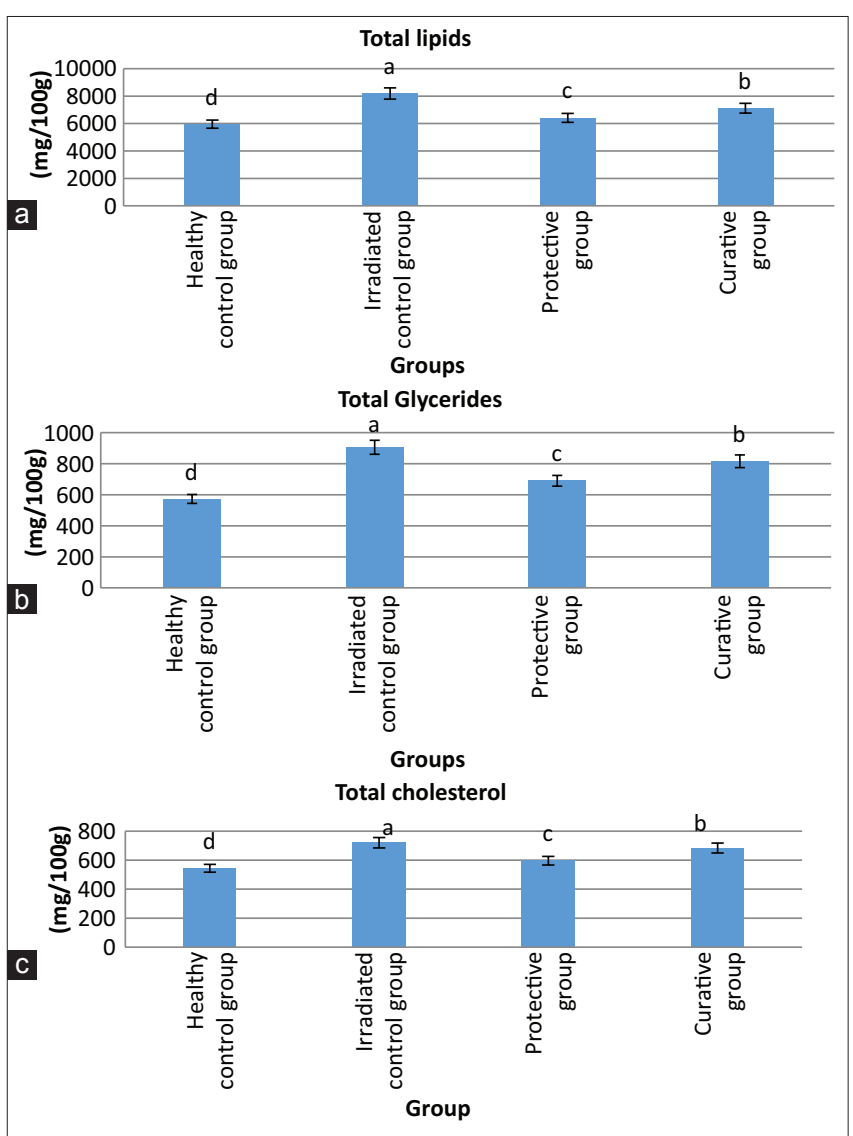

Fig. 5: Effect of protective and curative orange juice supplementation on hepatic lipid profile [total lipids (a), total glycerides (b), and total cholesterol (c)] levels in irradiated female rats. Values are expressed as means \pm standard deviation, $n=10$. Column of histogram with different letters is significantly different at $(p \leq 0.05)$

hepatic oxidative stress markers associated with increased hepatic antioxidants level and activities. From our results, it was obvious that pre-OJ supplementation strengthens the antioxidant system more effectively to fight generated ROS from IR when compared to post-0J supplementation, but in general, both treatments were effective.

As a consequence of oxidative damage that progressed to protein and DNA oxidation, inflammatory pathways were activated and increased inflammatory cytokines production assembled in recorded high hepatic TNF- $\alpha$ level that stimulated hepatic COX-2 activity and initiated PGE2 formation that supports inflammatory process and causes pain. A number of protein kinases and transcriptional factors regulated by TNF- $\alpha$ are contributing to the upregulation of COX-2. The expression of COX-2 mRNA and protein is often increased in different human cell types by inflammatory cytokines such as TNF- $\alpha$. Further, TNF- $\alpha$ induced PGE2 release so that arachidonic acid is metabolized into PGE2. PGE2 is an important lipid mediator of numerous physiological and pathophysiological processes through PGE synthase. In response to distinct pathophysiological situations, including inflammation, pain, and cancer, PG syntheses can be stimulated equally. PGE2 is without a doubt a major mediator of inflammation in various diseases [31,32]. As a consequence of oxidative stress and progressive inflammation of liver tissues, tissue fibrosis resulted and indicated by high collagen levels in liver and on long term may progress into cancer $[5,6]$.

OJ flavonoids and polyphenols have antioxidant and anti-inflammatory activities. Subsequently, OJ administration caused inhibition of COX-2 expression and blockage of pro-inflammatory cytokine TNF-alpha production and suppression of its associated inflammatory pathways resulting in PGE2 decreased and prevented production associated with the preservation of hepatic tissues from fibrosis by decreased collagen level.

Our results go hand in hand with previous studies [12,26-30], as a consequence of oxidative stress and inflammation of hepatic tissues, liver impairment and injury occurred and resulted in tissue degeneration resulting in increased liver's operational functioning enzymes (ALT, AST, and $\mathrm{y}$-GT) in serum. That progressed into gallbladder disease indicated by increased ALP activity associated with jaundice (increased bilirubin level). Owing to irradiation, degeneration of the hepatic tissues caused intracellular enzymes to be released into the serum due to cellular leakage and loss of functional integrity of the cell membrane. Increased hepatic enzymes have indicated that non-IR has a cytotoxic effect on hepatocytes, initiating apoptosis, and necrosis. Elevated oxyradical expression along with consequent cell membrane disruption was reported to be the reason for electromagnetic field-induced cell damage. OJ supplementation to irradiated female rats, either as a protective or curative treatment, has improved the hepatic functions and preserved hepatic tissues from degeneration. Protective supplementation with OJ strengthened tissues to the extent that decreased tissue damage associated with irradiation while curative supplementation decreased deleterious effects of irradiation on hepatic tissues and so the most improvements were recorded in the protective group.

Irradiation of female rats caused an increased level of total lipids, total cholesterol as well as total glycerides in hepatic tissues as a result of impaired lipid metabolism that may be due to decreased the esterification of liver cholesterol associated with decreased activity of lipoprotein lipase. Lipid accumulation inside hepatic tissues causes fibrosis of the liver cells leading to impairment of liver function and the disturbance in lipid metabolism could play a role in increasing lipid peroxidation and increased generation of ROS. The results of Rolle et al., Nada and Hawas and Martius et al. [3,33,34] confirmed our results that IR impaired lipid metabolism causing lipid accumulation inside the body, increasing the opportunity of fatty liver and cardiovascular diseases. OJ administration to irradiated rats normalized hepatic lipid metabolism and improved hepatic lipid profile in both pre- and post-supplemented groups when compared with the irradiated control group. OJ flavonoids, polyphenols, Vitamin $\mathrm{C}$, and folate normalized hyperlipidemia and hypercholesterolemia in human and experimental animals $[35,36]$.

In general, female hormones usually protect females health and prevent the progression of diseases, but in our study, it was clear that female hormones did not protect their bodies against radiation, but it may aggravate irradiation side effects these indications supported by other researchers [37-39] that concluded when exposed to the same dose of IR, women are more affected by IR and are considerably at greater risk of suffering and dying from radiation than men.

\section{CONCLUSION}

Due to its potent active components, $0 \mathrm{~J}$ holds the promise of protection and curation against radiotherapy side effects. $\mathrm{OJ}$ is cheap and presents almost all the year so, it is advised for people who are exposed to IR, especially females, as they are more prone to IR side effects, to consume on average $(5 \mathrm{ml}$ fresh $0 \mathrm{~J} / \mathrm{kg} /$ day) about (1.5 cup) especially before exposure to radiation and it is more advised to consume $0 \mathrm{~J}$ before and after exposure to radiation to attenuate and overcome IR side effects.

\section{AUTHORS' CONTRIBUTIONS}

Dr. Gehan M. Morsy and Dr. Alyae M. S. Gabal designed the study, made the protocol, managed the work done, performed the literature searches, and completed the manuscript writing.

\section{CONFLICTS OF INTEREST}

We declare that we have no conflicts of interest. 


\section{AUTHORS' FUNDING}

The authors funded the research.

\section{REFERENCES}

1. Youness ER, Agha FE, El-Toukhy SE, El-Naggar SM, Selim AI, Ibrahim AM. The protective effect of orange juice on glyphosate toxicity in adult male mice. J Chem Pharm Res 2016;8:13-28.

2. Dhakal D, Sharma KR. Estimation of total phenol and antioxidant activity of Zanthoxylum armatum of Nepalese origin. Int J Curr Pharm Res 2020;12:37-40.

3. Rolle AC, Veronique BV, Chupin J, Bouillot L. Nutritional composition of orange juice: A comparative study between French commercial and home-made juices. Food Nutr Sci 2016;7:252-61.

4. Abdallah IZ, Ahmed MM, Montaser SA, Hafez SS. Efficiency of kumquat fruit (Fortunella margarita) extract against hepatotoxicity and infertility induced by gamma irradiation in male albino rats. Egypt J Rad Sci Appl 2019;32:187-99.

5. Kim J, Jung Y. Radiation-induced liver disease: Current understanding and future perspectives. Exp Mol Med 2017;49:e359.

6. Nakajima T, Ninomiya Y, Nenoi M. Radiation-induced reactions in the liver-modulation of radiation effects by lifestyle-related factors. Int $\mathrm{J}$ Mol Sci 2018;19:3855.

7. National Research Council. Nutrient Requirements of Laboratory Animals. $4^{\text {th }}$ ed. Washington, DC: National Academy Press; 1995.

8. Khan RA, Mallick N, Feroz Z. Anti-inflammatory effects of Citrus sinensis L., Citrus paradisi L. and their combinations. Pak J Pharm Sci 2016;29:843-52.

9. Arnous A, Makrisand DP, Kefalas P. Effect of principal polyphenol components in relation to antioxidant characteristics of aged red wines. J Agric Food Chem 2001;49:5736.

10. Joyeux M, Lobestein A, Anton R, Morier F. Comparative antilipoperoxidant, antinecrotic and scavenging properties of terpenes and biflavones from ginkgo and some flavonoids. Planta Med 1995;61:126-29.

11. Brand-Williams W, Cuvelier ME, Berset C. Use of a free radical method to evaluate antioxidant activity. J Food Sci Technol 1995;28:25-30.

12. Cheng W, Xiao L, Ainiwaer A, Wang Y, Wu G, Bao Y. Molecular responses of radiation-induced liver damage in rats. Mol Med Rep 2015;11:2592-600

13. Draper HH, Hadley M. Malondialdehyde determination as index of lipid peroxidation. Methods Enzymol 1990;186:421-31.

14. Beutler E, Duroun O, Kelly BM. Improved method for the determination of blood glutathione. J Lab Clin Med 1963;61:882-8.

15. Reznick AZ, Packer L. Determination of protein carbonyl group content. Methods Enzymol 1994;233:263-57.

16. Paglia DE, Valentine WN. Studies on the quantitative and qualitative characterization of erythrocyte glutathione peroxidase. J Lab Clin Med 1967;70:158-69.

17. Misra HP, Fridovich I. The role of superoxide anion in the autoxidation of epinephrine and a simple assay for superoxide dismutase. J Biol Chem 1972;247:3170-5.

18. Kulmacz RJ, Lands WE. Requirements for hydroperoxide by the cyclooxygenase and peroxidase activities of prostaglandin $\mathrm{H}$ synthase. Prostaglandins 1983;25:531-40.

19. MacDonald RP. Serum total lipids assay. In: Standard Methods of Clinical Chemistry. Vol. 2. New York: Academic Press; 1970. p. 215-22.

20. Richmond W. Preparation and properties of a cholesterol oxidase from Nocardia sp. and its application to the enzymatic assay of total cholesterol in serum. Clin Chem 1973;19:1350-6.

21. Bucolo G, David H. Quantitative determination of serum triglycerides by the use of enzymes. Clin Chem 1973;19:476-82.

22. Levesque R. SPSS Programming and Data Management: A Guide for SPSS and SAS Users. $4^{\text {th }}$ ed. Chicago, IL: SPSS Inc.; 2007.

23. Haidari F, Keshavarz SA, Rashidi MR, Shahi MM. Orange juice and hesperetin supplementation to hyperuricemic rats alter oxidative stress markers and xanthine oxidoreductase activity. J Clin Biochem Nutr 2009; 45:285-91

24. Favela-Hernández J, González-Santiago O, Ramírez-Cabrera M, Esquivel-Ferriño P, Camacho-Corona M. Chemistry and pharmacology of Citrus sinensis. Molecules 2016;21:247.

25. Essa OS, Isamil AA, Moustafe AM. Histological and histochemical studies on the role of caffeine on radiation damage of the liver. Egypt $\mathrm{J}$ Hosp Med 2002;6:45-62.

26. Çakır T, Yıldızhan K, Huyut Z, Uyar A, Arıhan O. Radioprotective profile of Urtica dioica L. Seed extract on oxidative DNA-damage in liver tissue and whole blood of radiation-administered rats. Braz $\mathrm{J}$ Pharm Sci 2020;56:1-9.

27. Abd El Azime AS, El-Kabany H. Therapeutic and protection effectiveness of quercetin in $\gamma$-irradiated rats. Egypt J Rad Sci Appl 2011;24:217-27.

28. Abdelhalim MA, Moussa SA. The biochemical changes in rats' blood serum levels exposed to different gamma radiation doses. Afr J Pharm Pharmacol 2013;7:785-92.

29. Eid FA, El-Gendy AM, Zahkouk SA, El-Tahway NA, El-Shamy SA. Ameliorative effect of two antioxidants on the liver of male albino rats exposed to electromagnetic field. Egypt J Hosp Med 2015;58:74-93.

30. Nakajima T. Roles of sulfur metabolism and rhodanese in detoxification and anti-oxidative stress functions in the liver: Responses to radiation exposure. Med Sci Monit 2015;21:1721-5.

31. Azab K, Meky N, El-Deghidy E, Azoz G. Response of COX2/PGE2 inflammatory pathway to brown seaweed extract in rats exposed to gamma radiation. World J Nucl Sci Technol 2017;7:189-205.

32. Jang S, Lee S, Koo H, Lee J, Park Y, Namkoong S, Sohn E. Gamma irradiation-induced liver injury and its amelioration by red ginseng extract. Mol Cell Toxicol 2017;13:461-9.

33. Nada AS, Hawas AM. Rhubarb extract ameliorates some biochemical disorders induced by gamma irradiation in male rats. J Rad Res Appl Sci 2012;5:393-408.

34. Martius G, Alwahsh SM, Fränk MR, Hess CF, Malik AI. Hepatic fat accumulation and regulation of FAT/CD36: An effect of hepatic irradiation. Int J Clin Exp Pathol 2014;7:5379-92.

35. Kurowska EM, Borradaile NM, Spence MD, Carroll KK. Hypocholesterolemic effects of dietary Citrus juices in rabbits. Nutr Res 2000;20:121-9.

36. Ali Z, Naeem N, Farooq Z, Masood S, Hafeez-Urehmanf M. Effect on lipid profile parameters by the addition of orange juice in diet of hypercholesterolemic patients. J Nutr Food Sci 2015;5:428.

37. Biological Effects of Ionizing Radiation. Health Risks from Exposure to Low Levels of Ionizing Radiation, BEIR VII, Phase 2 Report. Washington, DC: The National Academy Press; 2006.

38. Marci R, Mallozzi M, di Benedetto L, Schimberni M, Mossa S, Soave I, et al. Radiations and female fertility. Reprod Biol Endocrinol 2018;16:112.

39. Narendran N, Luzhna L, Kovalchuk O. Sex difference of radiation response in occupational and accidental exposure. Front Genet 2019;10:260. 